analyses of results obtained in the Canadian Rocky Mountains indicate that the observations of deflection differences along the same line can be repeated with a precision of about $0.5^{\prime \prime}$, but there are systematic deviations between the forward and the backward running of the same line. A comparison with the available astronomically determined deflections also shows systematic differences of 2-3". Those discrepancies are most likely due to the 'overshooting' of the Kalman procedure at gradient changes. It appears that with certain software changes deflection differences between stations not more than half an hour of travel time apart can be determined by the inertial system, with an accuracy of better than $\pm 1^{\prime \prime}$

In the discussions it was brought up that we should have gravimeters with measuring accuracy \pm 1-3 $\mu \mathrm{Gal}$. In order to fully use this accuracy, we must compute accurately the effects of earth tides, have good models of effects of ocean tides and tidal loadings, and include different environmental effects into our modeling. We should also improve national and continental gravity standardization nets, by adding new absolute gravity measuring sites at appropriate locations and encouraging intercomparison of absolute gravity apparatuses. For calibrations of gravimeters, good calibration lines should be established, which include a sufficient number of absolute measurements to control the scale throughout the calibration line. As an end result of gravity anomaly determinations, we wish to have mean anomalies representing $100-\mathrm{km}$ wavelength field.

This report is based on one of the sessions at the Ninth Geop (Geodesy/Solid Earth and Ocean Physics) Research Conference, Columbus, Ohio, October 2-5. 1978.
The session participants were

Chairman U. A. Uotila, Ohio State University: Introduction and overview

J. C. Harrison, CIRES, University of Colorado, Boulder, and L. J. LaCoste, LaCoste \& Romberg, Inc., Austin, Texas: Surface gravity instrumentation;

J. A. Hammond and Robert L. Iliff, Air Force Geophysics Laboratory, Bedford, Massachusetts: The AFGL Absolute Gravity Program;

A. B. Watts, Lamont-Doherty Geological Observatory of Columbia University, Palisades, New York: Present status of marine gravity;

D. L. Turcotte, Cornell University, Ithaca, New York: Interpretation of geoid anomalies;

M. C. Roufosse, Smithsonian Astrophysical Observatory, Cambridge: Interpretation of altimeter data;

R. H. Rapp, Ohio State University: Comparison of surface and satellite data; and

K. P. Schwarz, University of New Brunswick, Fredericton: Accuracy of vertical deflection determination by present day inertial instrumentation.

This meeting report was prepared by U. A. Uotila, who is with the Department of Geodetic Sciences at Ohio State University.

The proceedings of the Ninth Geodesy/Solid Earth and Ocean Physics (Geop) Research Conference are available on microfiche. Order from American Geophysical Union, 2000 Florida Avenue, N.W. Washington D. C. 20009. Document E79007; \$1.00. Payment must accompany order. They are also available as a report. Order from The Onio State University, Department of Geodetic Science. $1958 \mathrm{Nei}$ Avenue, Columbus, Ohio 43210. Price: $\$ 10.00$. 6

\title{
AGU
}

\section{The William Bowie Medal: Citation and Acceptance}

\section{Citation}

The forty-first presentation of the William Bowie Medal goes to Frank Press for outstanding contributions to fundamental geophysics and for unselfish cooperation in research. Frank Press joins the ranks of the distinguished seismologists who have received the Bowie Medal. Reading the list of medalists takes one through almost the entire history of seismology. Previous medalists include James B. Macelwane, Harold Jeffreys, Beno Gutenbert, Maurice Ewing. Hugo Benioff, Louis Slichter, and Inge Lehmann, and it is appropriate that Frank Press is now a member of this distinguished group. You may know that Frank has worked with many of these people. As much as anyone, Press built the bridge from their classical tradition to what we look on today as modern seismology.

Sometimes one gets the impression that science consists of physicists, for physicists, by physicists. Some physicists look with disdain on a field that puts geo- in front of physics. Members of the American
Geophysical Union were especially gratified therefore by President Carter's remarks when he was introducing Press on the occasion of his swearing-in ceremony in the Rose Garden. The President commented that Defense Secretary Harold Brown 'is well-qualified in physics, and I particularly wanted someone to help how has a broader scope of understanding.' He certainly picked the right man.

We all know how effective Frank has been in his present job and how the President, along with all of us, has learned to trust his advice. The Bowie Medal, however, is given for scientific achievement. Frank can look back with immense satisfaction at his scientific accomplishments and at the number of people in this room who are his scientific family and close friends. 1 hope tonight he can put aside some of his weightier policy concerns and be immersed in good memories.

There are some interesting historical coincidences between Frank Press' career and the timing of previous awards. Beno Gutenburg of Cal Tech received the award in 1953, which may have been an element in Frank's decision to join the Cal Tech faculty in 1955 Just after Press left Columbia, Walter Bucher and Maurice Ewing received the award. The Bowie Medal stayed on the East Coast for some years, so in 1965 Frank moved to M.I.T.; whereupon Hugo Benioff back at $\mathrm{Cal}$ Tech received the award. This was followed by a series of West Coast medalists. Finally, Frank Press saw a Bowie Medal in 1976 when his colleague Jule Charney at M.I.T. was the recipient. Frank then left, of 
course, to go to Washington to become the President's Science Advisor and Director of the White House Office of Science and Technology Policy.

Frank Press was born in Brooklyn in 1924 and received his B.S. from the College of the City of New York in 1944. He obtained his Ph.D. in 1949 from Columbia University, and started a historic collaboration with Maurice Ewing at Lamont Geological Observatory. This collaboration resulted in a classic series of papers that started the present era of seismology. The theoretical and observational basis for surface waves and free oscillations was laid at that time. This work culminated in the discovery of the earth's free oscillations after the great Chilean earthquake in 1960. Interestingly, three Bowie Medalists, independently and at separate institutions, were involved in this discovery: Benioff at $\mathrm{Cal}$ Tech, Slichter at U.C.L.A., and Ewing at Lamont; and, of course, Press then at $\mathrm{Cal}$ Tech.

Press came to the Seismological Laboratory at Cal Tech in 1955, joining Beno Gutenberg. Hugo Benioff, and Charles Richter. His impact was felt immediately. He initiated a wide variety of projects which have had lasting impact, including crustal and surface wave studies, model seismology, seismic discrimination, and earthquake prediction. He soon had a large collection of graduate students who went off to populate the universities, government laboratories, and industry, both here and abroad. Frank is not only an innovator in science; he is also an innovator in how to educate scientists.

While at the Seismological Laboratory, Press pursued his surface wave studies and also discovered body waves. He instigated the now common procedure of jointly considering all available geophysical data in his construction of models for the crust and upper mantle. His crustal models of California are still used in routine locations of earthquakes. Moving on to even longer periods, Press showed that large earthquakes lead to measurable changes in the static displacement fields at teleseismic distances. He founded the science of D.C. seismology. I never understood this term; direct current doesn't seem to have anything to do with seismology. It only recently occurred to me that Frank, being the consummate politician, realized that the source of power was in Washington, D.C.

He succeeded Gutenberg as Director of the Seismological Laboratory in 1957. He had a great deal to do with the growth and maturing of geophysics in the following years. Instruments were placed around the world, large government programs started in crustal studies, discrimination, and lunar seismology. He was the prime mover in several international geophysical programs, including the exploration of Antarctica. Press was the major force behind all of these, both politically and scientifically.

These were exciting times in geophysics. In addition to Gutenberg, Benioff, Richter, and Dix, Cal Tech and the Seismological Laboratory were host to Jeffreys, Bullen, Tsuboi, Bath, Sato, Takeuchi, Aki, Hatherton, Hales, Knopoff, Weertman, and many others during this period. Great strides were made in seismic source theory, theory of wave propagation in the earth, circumPacific tectonics, structure of the upper mantle and core, long-period seismic instrumentation, computer applications, anelasticity, anisotropy, and leaky modes. Among the students being educated at this time were Lomnitz, Flinn, Healy, Phinney, Kovach, Alexander, BenMenahem, Archambeau, S. Smith, Tokoz, Harkrider, and Cisternas.
Much of modern seismology was started by Frank Press and the group that grew up around him; synthetical seismograms, use of computers in earthquake locations and dispersion calculations, digital seismometers, array studies, use of nuclear sources, lunar and planetary seismology, free oscillations, radiation from moving faults, detailed source theory, partial derivatives and inversion, studies of anelasticity, dislocation theory and mobile seismic arrays. Many modern seiomologists also grew out of this group. Frank Press' students and their students now permeate the geophysical scene.

During his Cal Tech years, Press authored 72 scientific papers. These included studies of the crust around the world, the viscosity of the core, development of the Press-Ewing seismograph system, model seismology, the low-velocity zone, development of a lunar seismometer, discovery of the free oscillations, release of tectonic strain by nuclear explosions, discovery of acoustic-gravity waves, diagnostic techniques for seismic discrimination, seismic wave attenuation, static changes at teleseismic distances, and earthquake prediction.

He also did a few things later at M.I.T., but it is too early to judge the significance of these. His number of papers and books is now over 150. This is pretty good for someone who has been an administrator for 20 years, including 11 years as chairman of the Department of Earth and Planetary Sciences at M.I.T. Monte Carlo inversion, lithosphere studies, and pattern recognition applied to prospecting and earthquake prediction were important breakthroughs he made during this period. He also found time to write what has been called the best geology text in $\mathbf{5 0}$ years. I can attest from personal experience that freshmen love it. Even though Frank is temporarily out of academia, his role in educating students continues through the vehicle of this book, coauthored with Raymond Siever of Harvard, and named after his second love, Earth.

Press has, of course, served on many committees, councils, panels, working groups, and boards. Most scientists have. The difference is this. When Frank Press was involved, something significant invariably was accomplished. International programs were started, major new national initiatives were taken, instruments were placed around the world, on the moon and on Mars, technical problems associated with discrimination were solved. Good things and important things happened. Frank Press is, above all, an effective leader and spokesman. I have never known his advice to be wrong. I have never known his vision to be clouded. Science in this country is in good hands. The country can only benefit.

Don L. Anderson

\section{Acceptance}

If I may be permitted to admit of an imperfection of character, let me say that I have coveted the Bowie Medal and I have hoped it would come my way while I could still walk to the dais. I take it as a special honor to be selected for the highest award from the American Geophysical Union. The Union is the one scientific society that has meant the most to me professionally and personally in the course of my career. I have attended just about every meeting since 1946 when I presented my first scientific paper. There's something 
about the AGU meetings that generates excitement, currency, and intensive communication. Perhaps it is because the field of geophysics is in a golden period of great new discoveries and syntheses. Perhaps it is because the AGU has encouraged young people not only to attend, but to mix in and debate with their elders. Perhaps it is because special sessions are always arranged, which crosscut several interacting fields, which demonstrate the basic unity of geophysics, and counteract the natural tendency toward overspecialization. The one frustration of AGU meetings is the daily need to decide which of so many fascinating sessions to attend.

My own career, like that of so many scientists, was molded by interaction with great men. It was my fortune as a beginning scientist to cast my lot with Maurice Ewing in the early days of the creation of the Lamont Observatory. By example, rather than by lecturing, Ewing taught me the following:

- Make a better instrument or measure in a place where no one else has been and a great discovery will come your way.

- Do not hesitate to enter new fields despite the giants who may be your competition, for it is the fresh analysis from a different vantage point that often leads to important new insights.

- Competition is a good word and the fun and excitement of being first should be relished.

- Nature does not give up her secrets lightly, and hard work, long hours, personal commitment are essential ingredients to scientific discovery.

Finally, Ewing generated an excitement and created an electrifying atmosphere of imminent discovery that his students and coworkers could never forget and would try to recreate in their own institutions.

When I moved to Cal Tech I had the extraordinary opportunity to work with Gutenberg, Richter, and Benioff, three distinct and entirely different characters. From Gutenberg, I learned to be patient with enormous amounts of scattered data, which contained important secrets if one had the patience to unravel them. Richter taught me the importance of filing away in one's mind seemingly extraneous facts, which if exhumed at the right time, in the right context, would form the keystone of an important discovery. Benioff taught me to be skep tical, uninhibited in throwing out new ideas and, of course, the power of a new instrumental technique.

At $\mathrm{Cal}$ Tech and M.I.T. my association with a large number of gifted and dedicated students, who were really not students but colleagues, multiplied enormously my own scientific contributions. I found that the secret of producing successful graduate students goes beyond working with only the smartest ones. It involves pointing them toward fields ready for major discoveries, making available to them state-of-the-art instruments, treating them with the dignity and respect worthy of research partners, and maintaining the tension of imminent discovery that Ewing created in his research group.

The Bowie Medal is awarded for unselfish cooperation in research. In a real sense my wife Billie should be a corecipient of this award for the unselfish way she put up with my absences and my preoccupation with my profession in the early years of our marriage and even more so in the past 2 years in Washington. Come to think of it the wives of some of the past recipients were better able to meet the criterion of unselfish cooperation than their husbands.

I have watched this award being made for some 30 years now to some of the great men of our field. It is an honor to be numbered among them and I am grateful to the nominating committee, to the Council, and to the President of the American Geophysical Union for selecting me and reminding me of the great pleasure and fulfillment I have enjoyed as a member of this exciting profession.

\section{The Fleming Medal-Citation and Response}

\section{Citation}

It would be difficult to find a more worthy candidate for the Fleming Medal than Syun-Ichi Akasofu. Currently professor of geophysics at the University of Alaska, a post he has held since 1964 , he typifies the physics of the aurora to the space science community. Syun was born in Nagano-ken, Japan, on December 4, 1930. He received his B.S. degree in geophysics from Tohoku University in Sendai, Japan in 1953 and his M.S. in 1957 from the same university. He came to the University of Alaska and was appointed research assistant in 1958 where he became a long-term associate of Professor Sydney Chapman. He received his Ph.D. in 1961 at Alaska.

Syun is perhaps best known as a synthesizer and for his concept of the 'auroral substorm,' which was first proposed by him in 1964 but which he conceived as an idea as early as 1961 . With the aid of this concept, the global features of the aurora to a large extent became unified. The substorm idea called attention to the time progression of auroral storms, which develop in a cyclic manner during the main phase of geomagnetic storms. The auroral or magnetospheric substorm has come to be regarded as the process by which energy is stored in the magnetosphere from the sun and periodically released into the terrestrial upper atmosphere. Syun has not only carried out numerous and extensive analyses of auroral and geomagnetic data in developing these concepts, but has also been a leader in understanding the detailed physics of the auroral precipitation, acceleration, and the large-scale plasma processes, which in the magnetosphere couple the energy into the earth's atmosphere.

Syun is a prolific and untiring author and has produced nearly 300 papers, five books, and numerous major review articles, such as the 'Dynamics of the Aurora' in the Annals of the IGY. His most recent book was published in 1977 on 'The Physics of Magnetospheric Substorms,' and the vast number of papers which now exist on the subject and which serve as the substance of this second treatise on substorms by the same author testify to the fruitfulness of the idea.

One of the highlights of the first decade of the space era was the collaboration of Syun-Ichi Akasofu and Sydney Chapman which led to the volume on 'Solar Terrestrial Physics' published in 1972. In January 1976, Syun was the second recipient of the newly established Chapman Medal of the Royal Astronomical Society in England, and in March 1977, he received the Japan Academy Award for his studies of magnetospheric physics. He was the convenor of the recent AGU Chap- 